\title{
PROPOSTA METODOLÓGICA PARA REVISÃO OU CONSTRUÇÃO DE GRADES CURRICULARES COMPATÍVEIS COM A FORMAÇÃO PROFISSIONAL PARA O MERCADO E PARA O DESENVOLVIMENTO REGIONAL
}

\author{
Marcos Elias Traad da Silva ${ }^{1}$
}

\begin{abstract}
Resumo
A formação profissional para o trabalho é uma meta do educador, haja vista a demanda por serviços qualificados em diferentes segmentos da economia e as suas relações com o desenvolvimento de diferentes regiões do país. Segundo a Lei n. ${ }^{\circ} 9.394$ (20/12/96) de Diretrizes e Bases da Educação Nacional (LDB), a educação para o trabalho envolve profissionais em nível técnico (médio) e tecnológico (superior). Esses devem estar aptos à prestação de serviços, com o desenvolvimento de competências e habilidades inerentes à sua profissão. Assim, o principal meio pelo qual os futuros profissionais estarão aptos ao trabalho é orientado pela grade curricular do curso. Muitas vezes, ela não é concebida metodologicamente para atendimento ao mercado, tampouco direcionada à visão crítica do ambiente de trabalho e da sociedade como um todo. Isso significa que, mesmo contendo disciplinas relevantes, a grade nem sempre atende a esta dinâmica, devendo ser reavaliada, ou construída, com base em parâmetros importantes. Objetiva-se, assim, sugerir metodologia para a construção de grades curriculares, buscando-se o desenvolvimento de competências e habilidades, destinadas ao exercício profissional para o trabalho, com maior integração entre os professores de um curso, e entre esses e a futura profissão dos egressos.
\end{abstract}

Palavras-chave: Currículo; Formação profissional; Metodologia curricular.

\section{Abstract}

Job professional training is an important goal to the educator, as there exist strong relationship with regional development. According to the law $\mathrm{n}^{\circ}$ 9.394, Bases and Directions for National Education (LDB), from 20 December 1996, job training education includes professionals at the undergraduate technical, and graduate technological levels. Both categories should be well prepared to offer services, through competence and ability development, inherent to their courses. Therefore, the well and carefully devised list of required courses for a given career is the main strategy to warrant future professionals that will be prepared for their job. In many cases, this list of required courses are not organized following job market demands. This means that, even with relevant disciplines for a department, the overall offer of them do not attend the dynamics of job market. Thus, this list should constantly be reevaluated. This paper intends to propose a methodology to properly build the list of sequential courses to fulfill a curriculum to better adjustment for the needs of the job market, and for the abilities of those going to graduation.

Keywords: Curriculum, Professional development, Curriculum building.

Zootecnista, MSc., Professor do Centro de Ciências Agrárias e Ambientais Rua Vereador Augusto Staben, 370, Bacacheri, CEP 82.515-240, Curitiba, PR traad@pr.gov.br 


\section{Introdução}

Um dos grandes entraves à formação de nível médio (técnica) ou universitária (tecnológica), com qualificação que atenda às características do mercado de trabalho, consiste no próprio processo de construção da grade curricular, que normalmente não é orientado para os desafios que os futuros profissionais deverão enfrentar no seu dia a dia. Tendo em vista que um dos fatores que interferem na melhoria dos indicadores sociais é a qualidade dos serviços prestados em diferentes áreas, é oportuno afirmar que a formação de profissionais pouco capacitados para interagir com a sociedade pode ocasionar um retardamento ainda maior no desenvolvimento regional.

Neste sentido, alguns referenciais básicos para a estruturação do conhecimento relacionado às atividades profissionais têm sido insistentemente buscados, tendo como marco fundamental a constituição de uma das principais etapas de um projeto pedagógico, qual seja, a elaboração das grades curriculares dos cursos. Além disso, é preciso enfatizar que a concepção do currículo deve atender a uma condição básica de flexibilidade, de tal forma que, segundo Goleman (1995), "possa levar os alunos a fazer opções inteligentes, de acordo com objetivos e projetos individuais".

Segundo Moran (1999), é importante que o educador possa gerenciar divergências e diferenças individuais, na medida em que: "Avançaremos mais, se soubermos adaptar os programas previstos às necessidades dos alunos, criando conexões com o quotidiano, com o inesperado, se transformarmos a sala de aula em uma comunidade de investigação". O mesmo autor evidencia que: "Não podemos dar aula da mesma forma para alunos diferentes, para grupos com diferentes motivações", o que ratifica a condição de que haja flexibilidade numa grade curricular e na forma de abordagem das matérias pelo docente.

Normalmente, verifica-se uma relativa semelhança entre currículos dos cursos de uma determinada profissão em diferentes Instituições de Ensino Médio (IEM) ou Superior (IES), uma vez que o seu processo de elaboração não utiliza metodologia específica, observando-se, na realidade, uma tentativa de organização de disciplinas (muitas vezes com denominação diferenciada; outras, com seus conteúdos ora estreitamente relacionados, ora com particularidades que impedem o seu aproveitamento em processos de transferência tanto dentro, quanto entre cursos), no afã de que seja obtida apenas uma seqüência lógica para o aprendizado. Isso pode indicar alguns pontos importantes para uma reflexão, sendo que o primeiro diz respeito às questões que envolvem a legislação profissional, definida pelos conselhos de fiscalização das profissões, que costumam homologar habilitações, definidas por lei, caso o profissional tenha cursado uma ou outra disciplina com seus respectivos conteúdos. Essas, analisadas em separado e mescladas entre si, podem dar origem a uma outra grade curricular modificada para uma situação especial, num simples ensaio de "adaptação mecânica”, sem a desejável orientação para um processo de construção.

Várias têm sido as interpretações do conteúdo da Lei n. ${ }^{0} 9.394$ (20/12/96) de Diretrizes e Bases da Educação Nacional (LDB), o que tem causado certa disparidade em questões conceituais que devem nortear as atitudes dos educadores do país.

É preciso, portanto, que hajam iniciativas e estudos dirigidos à definição de metodologias para a real construção da grade curricular de um curso qualquer, compatível com a formação para o trabalho e para o aprimoramento intelectual do profissional cidadão.

Assim sendo, objetiva-se basicamente, com este breve relato, evidenciar alguns elementos teóricos e metodológicos (extraídos de escassa literatura sobre o assunto, e com base na experiência pessoal do autor, como consultor em projetos específicos sobre o tema), como contribuição para a concepção de grades curriculares. Esses podem ser utilizados como referenciais iniciais na busca de formas dirigidas à aquisição de conhecimentos para o aprendizado e para a formação de competências e habilidades, importantes para o acesso ao mercado de trabalho pelos egressos de cursos de formação profissional.

\section{Conceitos e definições importantes}

O processo de construção de uma grade curricular deve atender ao estabelecido na LDB, em seu artigo primeiro, parágrafo segundo: " $A$ educação escolar deverá vincular-se ao mundo do trabalho e à prática social". Da mesma forma, devese evidenciar o descrito no art. 6. ${ }^{\circ}$, item III, do 
Decreto n. ${ }^{\circ} 2.208$ (17/04/97), que regulamenta o Parágrafo $2{ }^{\circ}$ do artigo 36 e os artigos 39 a 42 da LDB, relacionados ao ensino técnico: "o currículo básico (...) para que os estabelecimentos de ensino, independente de autorização prévia, elejam disciplinas, conteúdos, habilidades e competências específicas da sua organização curricular". Note-se que é possível, a critério do estabelecimento de ensino, eleger disciplinas, conteúdos, habilidades e competências específicas. Ora, se isso for adotado como um mero exercício de escolha, sem a necessária construção do currículo do curso, é evidente que a formação profissional será orientada pela arbitrariedade de quem formatou a grade curricular.

Refere-se, o mencionado artigo da LDB, ao mundo do trabalho e à prática social. É razoável, portanto, que o educador tenha também como meta vinculada à sua missão a formação de cidadãos compromissados com o ambiente social no qual estarão atuando. Desta forma, a construção de uma grade curricular deve considerar tais aspectos, sob pena de, em caso contrário, habilitar os futuros profissionais exclusivamente para o trabalho. Essa condição é bem caracterizada, inclusive quando nos reportamos ao contido na Declaração Mundial Sobre Educação Superior (UNESCO, 1998), em seu artigo $7^{\circ}$ (Reforçar a cooperação com o mundo do trabalho, analisar e prevenir as necessidades da sociedade), item a, quanto às missões e funções da educação superior, ou seja: "em economias caracterizadas por mudanças e pelo aparecimento de novos paradigmas de produção baseados no conbecimento e sua aplicação, assim como na manipulação de informação, devem ser reforçados e renovados os vínculos entre a educação superior, o mundo do trabalbo e os outros setores da sociedade".

Os termos competências e habilidades também devem ser analisados, podendo-se buscar o seu significado nato, conforme o estabelecido por BUENO (1996), que os define como: substantivos femininos, tendo a primeira significado que expressa "aptidão, capacidade", e a segunda "inteligência, capacidade, jeito, destreza, conbecimento técnico".

Alguns conceitos importantes são descritos em proposta apresentada em BRASIL (1997), adaptados por PARANÁ (s.d.), para cursos de formação técnica profissional. Segundo essa fonte, os egressos desses cursos deverão adquirir com- petências e habilidades, para o exercício de funções que podem ser definidas como "macro atividades que o técnico deverá desenvolver no exercício da sua profissão, cujo número varia conforme a profissão, sendo que uma função poderá gerar diversas sub-funções. Essas, definidas como "frações das macro atividades que o futuro profissional deverá estar apto à exercer no mercado de trabalho". Outro termo de suma importância para o entendimento sobre como são adquiridas as competências e habilidades, também sugerido em PARANÁ (s.d.), diz respeito às bases tecnológicas, que são os "conteúdos das disciplinas propriamente ditas, que serão ministradas na educação profissional, componentes da grade curricular".

Definidas algumas palavras-chave, é preciso evidenciar que o processo de construção da grade curricular adotado pelas IEM e IES deve perseguir a meta de alicerçar as competências e as habilidades necessárias ao bom exercício das profissões, sem as quais não haverá evolução na sociedade atendida pelos egressos dos cursos, tampouco resposta do mercado de trabalho com a abertura de espaço aos profissionais, o que tem sido denominado de empregabilidade.

Na concepção de MARQUES (1998), algumas características essenciais são importantes para assegurar a inserção exitosa de profissionais no mundo do trabalho, tais como: "autoconhecimento, habilidades que decorrem de uma sólida educação básica e visão de mundo aberta para a aceitação da pluralidade e das diferenças". Isso indica que a concepção da grade curricular deve também considerar o desenvolvimento das citadas particularidades, o que, convenhamos, não é simples de ser alcançado.

De acordo com Botomé (1999), "o que os alunos precisam aprender a realizar em seu ambiente de vida e de atuação é derivado do conbecimento". É importante, por conseguinte, que o processo de transmissão do conhecimento do professor ao aluno tenha como objetivo básico a capacitação para o exercício das funções, que são inerentes à cada profissão.

Tem-se, pelo exposto, um esboço inicial sobre a conduta teórica que pode balizar a construção de um currículo de uma dada profissão, restando, entretanto, a seguinte pergunta:

- Como, então, é possível orientar a elaboração de uma grade curricular, objetivando-se a 
aprendizagem, tendo como conseqüência a formação para o trabalho, com condições de interpretação e interferência no ambiente social?

\section{Importância e significado da grade curricular}

Pode-se definir a grade curricular de um determinado curso como a estrutura que contém um elenco de disciplinas, listadas com suas respectivas cargas horárias, agrupadas em determinada ordem lógica, em sistemas geralmente semestrais ou anuais, que devem possibilitar a evolução da aquisição do conhecimento, transformado em aprendizagem.

Desta simples definição, pode-se depreender que: uma grade curricular tem que ser ajustada ao avanço gradativo do conhecimento adquirido pelo estudante. Mais ainda: deve ser organizada de tal forma que o aprendizado numa etapa anterior possa ser utilizado como suporte e ponto de partida para uma etapa subseqüente, com a finalidade de que haja a evolução do aluno na sua formação profissional. Deve ser ainda mencionado que muitas vezes existe a possibilidade de construção do conhecimento correlacionado num mesmo período (semestre ou ano), tendo-se como base outras disciplinas, que podem ser oferecidas de forma concomitante.

Sabendo-se que a grade curricular é o instrumento por meio do qual as disciplinas são organizadas, para que os professores possam instruir aos alunos no aprendizado, pode ser arriscado ao extremo afirmar (por uma série de fatores) que, se houver minuciosos estudos sobre a forma pela qual as disciplinas devem ser agrupadas (no sentido da construção do conhecimento), haverá êxito direta e positivamente correlacionado ao aprendizado. Isso deve ter como argumento precípuo o fato de que uma determinada disciplina deve, por si só, conter uma lógica própria (baseada no elenco de conhecimentos correlatos, intrín-secos a ela), o que rotineiramente denomina-se de conteúdo.

É importante ressaltar que a simples enumeração de conteúdos num dado programa de ensino não é suficiente para que haja aprendizagem, pois a concepção de conteúdo, por si só, de acordo com Botomé (1999), não deve "ignorar a relação entre conbecimento produzido (as infor- mações ou os conteridos) e o que os alunos precisam ou devem ser capazes de realizar com o conhecimento (ou a partir dele)". O mesmo autor caracteriza inclusive que o termo conteúdo de uma dada disciplina deveria ser definitivamente abolido, tendo em vista que, a partir do conhecimento existente, deve ser objetivo maior do educador a busca do desenvolvimento de aptidões dos estudantes. Essas "deverão constituir a capacidade de operar própria e característica de uma responsabilidade social básica e geral (e específica, como no caso das profissões)". Defende ainda a tese de que o educador deve estar voltado à promoção do aprendizado, para tornar o profissional apto ao exercício das suas atividades no mercado de trabalho. Assim, caracteriza que é necessária a substituição de conteúdo de uma dada disciplina, para programa de aprendizagem. Esse pode ser inclusive o resultado da articulação de diferentes "disciplinas", haja vista que "deve traduzir aquilo que o aprendiz deve aprender e não somente o que o conteúdo propriamente dito deve conter", numa alusão clara ao fato de que é preciso conceber o que deve ser apresentado ao aluno como um plano de ensino.

Independente da forma como é denominado o conjunto de conhecimentos em uma determinada área, que deve ser objeto de análise pelo docente para ser apresentado aos alunos, é necessário que sejam feitas reflexões sobre o processo de constituição dos conteúdos específicos de uma dada disciplina. Esses sim, se utilizados como instrumento articulado ao aprendizado contínuo pelo aluno na sua vida profissional, poderão derivar em avanços no saber. Por conseguinte, a inclusão de determinados conteúdos, em determinadas disciplinas, pode ser um exercício de construção, feito com metodologia própria, que corrobora com a concreta obtenção de habilidades específicas, no sentido do desenvolvimento de competências ou aptidões.

Para que haja maior clareza sobre o exposto, podemos induzir o leitor a um exercício rápido, tentando evidenciar como construir competências e habilidades a partir de conteúdos de uma dada disciplina. Exemplificando, utilizemonos de um caso de uma disciplina intitulada Nutrição Animal, para alunos do Curso de Zootecnia. A referida disciplina deve ser um dos instrumentos pelos quais o acadêmico estará habilitado para orientar um criador de vacas leiteiras sobre a me- 
lhor estratégia de utilização dos recursos alimentares de que dispõe na propriedade. Para tanto, devem estar bem alicerçados os conceitos que o aluno obteve com algumas áreas básicas do conhecimento, que naturalmente lhe deram suporte para a definição de um roteiro planejado de atitudes, que resultarão na medida necessária, ou seja: na recomendação técnica mais adequada para o caso em pauta.

Para que isso ocorra concretamente (e este tem sido o real desafio dos educadores) é evidente que a condição de continuidade do aprendizado tem que servir de base à evolução entre os diferentes níveis pelos quais devem passar os alunos. Acrescente-se ainda que a formação profissional para o trabalho deve ser baseada na consolidação de uma ampla visão de fatores e variáveis que interferem nos sistemas produtivos, o que muitas vezes é obtido por meio de aulas práticas e atividades complementares. Essas, pelo exposto, devem ser voltadas ao desenvolvimento das habilidades que servirão de base para o mapeamento e consolidação de estratégias para a abordagem de um dado problema verificado pelo profissional formado.

Outra questão de extrema relevância, que normalmente não é considerada nos cursos, tem relação direta com a carga horária das disciplinas, que muitas vezes é excessiva. Essa constatação é relatada em BRASIL (1999), em trabalho apresentado pela Comissão Nacional de Ensino da Zootecnia (CNEZ), da seguinte forma: "A vivência acadêmica não pode estar restrita ao universo das disciplinas ministradas. A participação dos discentes nas pesquisas desenvolvidas pelos docentes e pós-graduandos das diferentes IES é necessária, assim como, nas atividades culturais e de extensão promovidas. Todavia, inúmeras vezes a carga horária das disciplinas impede ou secundariza estas atividades".

\section{A formatação da grade curricular pas- so a passo, com vistas ao desenvolvimento de competências e habilidades e à definição das funções do profissional}

Conforme o mencionado, é preciso que tenhamos em pauta que o egresso de um curso de formação profissional deverá estar apto para ocupar espaço no mercado de trabalho. Isso por meio de iniciativa própria (gerindo os seus negócios) ou pelo acesso direto ao exercício profissional, com vínculo empregatício. Isso indica que medidas acertadas na construção da grade curricular do curso dependem de consulta ao próprio mercado, o que deve ser feito periodicamente no sentido da adequação das disciplinas oferecidas, frente à evolução das demandas por serviços diversos dos profissionais. Este deve ser o primeiro passo na busca de respostas para alguns pontos essenciais, quais sejam:

- Qual o perfil atual dos profissionais egressos de um curso profissionalizante qualquer?

- Que problemas mais freqüentes são verificados com o exercício de uma dada profissão, para o atendimento efetivo aos anseios dos empregadores (se este for o caso - nível de satisfação pelos serviços prestados)?

- Quais as atuais deficiências dos profissionais que devem ser corrigidas, para que haja avanços qualitativos na prestação de serviços (situações problema)?

- Qual o perfil do profissional que a sociedade está exigindo atualmente?

- Enfim, a estruturação de levantamentos/pesquisas, cujas respostas devem ser utilizadas como orientadoras do processo de produção do currículo, devendo-se enfatizar, também, a importância do acompanhamento da velocidade das transformações ocorridas em diferentes áreas, com vistas à antecipação de tendências.

Concluída a fase da pesquisa, é de vital importância e absoluta relevância a adoção de critérios lógicos para a identificação das funções e sub-funções que devem ser contempladas para a formação profissional específica.

Tenhamos como referencial um curso de formação tecnológica, cuja consulta ao mercado nos indicou vários itens relacionados com a função planejar. Para que haja atendimento ao nível de formação em pauta, qual seja, o desenvolvimento de competências (ou aptidões) voltadas ao planejamento, é preciso elaborar um processo de produção, cujo resultado seja a constituição das mencionadas competências, com a definição das habilidades (destreza ou, de acordo com PARANÁ (s.d.), o saber fazer) para a função planejar. O nível ou o objetivo primordial do planejamento será definido por uma sub-função qualquer (ex.: planejar as etapas do controle de um rebanho de bovinos utilizados para a produção de carne). 
Façamos, então, um rápido exercício no sentido da definição de funções, sub-funções, competências e habilidades (PARANÁ, 1998). Suponhamos que um profissional qualquer deva estar apto para exercer uma função:

- Função 1: Gestão e controle

A Função 1 pode ser desmembrada, resultando em sub-funções. Imaginemos, então, algumas delas:

- Sub-função 1.1: gerência de recursos humanos.

- Sub-função 1.2: gerência de produção.

- Sub-função 1.3: gerência de máqui-

nas.

- Sub-função 1.4: gerência comercial.

- Sub-função 1.5: controle de estoques etc.

Enfim, um elenco de atividades correlatas a uma dada função que devem ser gradativamente descritas, na busca da definição de competências para a sua execução.

Concebidas criteriosamente todas as subfunções, é necessário, por conseqüência, dar seguimento ao processo de construção do currículo da profissão, levantando-se as competências relativas. Exemplificando, podemos definir para a Subfunção 1.1 (gerência de recursos humanos) algumas das seguintes competências:

- Competência 1: conhecer técnicas de trabalho de grupo;

- Competência 2: conhecer técnicas de comunicação verbal;

- Competência 3: conhecer noções de legislação trabalhista etc.

$\mathrm{O}$ fato de o aluno adquirir as mencionadas competências não significa que ele saiba transformá-las em atitudes de cunho prático, ou seja: o saber fazer. Faz-se necessário, portanto, definir quais habilidades devem ser desenvolvidas para uma ou mais compe-tências listadas. Assim, poderíamos listar as seguintes habilidades:

- elaborar planos de treinamento em gru-

po; audiovisuais;
- coordenar equipes de trabalho;

- desenvolver programas de inter-relacionamento de pessoas em uma organização etc.

Com os exemplos apresentados, fica evidente o fato de que para a obtenção das habilidades relativas a uma dada profissão, com base na consulta prévia às demandas mercadológicas e sociais, deve-se abolir a simples adequação de grades curriculares, uma vez que para a constituição dos conteúdos das disciplinas (doravante definidos como bases tecnológicas) é necessário identificar que componentes são importantes à formação profissional, para serem inseridos num plano de ensino pelo docente.

A etapa subseqüente, então, deverá ser a definição das bases tecnológicas componentes das disciplinas de formação profissional do curso, no sentido do desenvolvimento de competências e habilidades. As bases tecnológicas são compostas por conhecimentos tecnológicos (em áreas específicas) e por conhecimentos de matérias necessárias ao exercício da profissão, tais como legislação, resoluções, normas técnicas (PARANÁ, s.d.). Exemplificando, poderíamos ter algumas das seguintes bases tecnológicas inerentes à Função 1 e Sub-função 1.1:

- Técnicas de trabalho em grupo. Técnicas de motivação.

- Tipos de recursos audiovisuais.

- Técnicas de comunicação verbal e es-

crita.

- Noções de ética.

- Legislação trabalhista etc.

Note-se que as bases tecnológicas apresentadas podem ser componentes de diferentes disciplinas, o que induz à necessidade de que, quando as mesmas tenham sido integralmente levantadas, sejam agrupadas dentro das disciplinas do curso, formando o programa ou o plano de ensino buscado e necessário à formação para o trabalho.

Tendo em vista que as bases tecnológicas podem manter relação com o conhecimento básico que dá suporte à sua constituição, é evidente que deve-se procurar identificar quais áreas básicas são necessárias ao curso em pauta, sem o que não poderá haver a almejada sinergia com o aprendizado, para a estruturação das competências e 
habilidades no profissional egresso. Essas áreas do conhecimento básico adquirido ao longo da vida acadêmica do estudante nos diferentes níveis de estudo pelos quais passou são definidas como bases científicas e bases instrumentais (PARANÁ, s.d.). As primeiras, consideradas como as disciplinas nas áreas científicas (química, matemática, biologia, física etc.), além de disciplinas de continui-dade dessas, que poderão ser contempladas no decorrer do curso em questão (bioquímica, biofísica, cálculo, matemática financeira, fisiologia etc.). As outras, tratadas como as disciplinas relacionadas às ciências humanas (história, filosofia, língua portuguesa, psicologia etc.), bem como as que abordam questões relativas ao exercício profissional propriamente dito, servindo de instrumentos ao egresso na sua conduta diária (código de ética, leis e resoluções, normas técnicas, etc.).

Os passos seguintes serão dados no sentido da conclusão do processo de construção, descrevendo-se as tarefas que deverão ser executadas, os níveis de autonomia e responsabilidade dos futuros profissionais (com base na legislação profissional vigente), relacionamento, além da definição dos meios e recursos que são necessários ao egresso, bem como os resultados que deverão ser exigidos com o exercício de uma dada subfunção, compreendida numa função. A grade curricular, pelo exposto, é então definitivamente construída, num processo que deve envolver todo o corpo docente da instituição de ensino, reunido em atividades conjuntas (oficinas de trabalho), para que seja buscada a interação dos grupos com o curso como um todo.

Uma vez que a construção da grade curricular, segundo a metodologia proposta, deve ser resultante de um trabalho coletivo, envolvendo o corpo docente, suas finalidades específicas na formação do profissional tornam-se mais conhecidas por todos, havendo, em tese, convergência das ações na melhoria da qualidade do curso. Isso significa dizer que, mesmo que um professor de uma das disciplinas de nível básico do curso não tenha uma concepção integral sobre as futuras atividades do profissional que está ajudando a formar, ele vai passar a conhecer melhor as reais funções e sub-funções que o egresso deverá estar apto a exercer na vida futura.

Esse problema tem sido alvo de discussões no meio docente, e várias têm sido as tentativas de integração entre os ciclos básico, interme- diário e profissional, dos cursos de formação para o trabalho, com vistas inclusive ao estímulo do aluno desde o início do seu curso, evitando-se ainda a própria redução da evasão. Por meio da construção conjunta da grade curricular, pode-se vislumbrar caminhos para a solução da desconexão entre diferentes estágios do curso, pelo menos hipoteticamente, o que deve estar estreitamente associado ao constante exercício na constituição de grupos de debates e de pesquisas entre docentes.

Como referencial de prioridade aos que terão como missão a construção da grade curricular, deve-se enaltecer que as disciplinas do curso deverão ser utilizadas como indutoras da visão crítica do profissional, da criatividade, para a busca de soluções alternativas, e do fortalecimento das habilidades como reais instrumentos de mudanças do panorama econômico e social de diferentes regiões ou comunidades onde estejam prestando seus serviços.

Pode-se ainda, com base na pesquisa do mercado demandador de um dado profissional e tendo-se a visão global do currículo do curso, configurar a grade curricular construída num sistema modular. Este sistema permite a organização das disciplinas do curso em grandes áreas do conhecimento consideradas fundamentais para a formação do profissional. De acordo com BRASIL (1999), "esta nova forma de ministrar conbecimentos, em grandes áreas que estabelecem uma interface entre o básico/profissionalizante, parte da premissa de um efetivo envolvimento dos docentes que compõem cada módulo, que poderão passar a atuar em todas as disciplinas do seu grupo, e de um cotejamento das ementas das disciplinas envolvidas, permitindo a não repetição dos conteúdos".

\section{Conclusões}

O processo de elaboração da grade curricular de um determinado curso de formação profissional deve ser resultante da consulta aos diferentes segmentos do mercado que demandará os serviços do futuro profissional. Para tanto, é necessária a adoção de metodologia adequada, no sentido da construção da grade curricular, muito além de um simples arranjo de disciplinas, o que pode resultar em inúmeros benefícios, entre os quais pode-se destacar: 
- maior direcionamento dos conteúdos das disciplinas ministradas, no sentido de serem abordados temas de uso intensivo no dia a dia do egresso do curso;

- maior integração entre os níveis básico, intermediário e profissional do curso, num evidente processo de estímulo ao aluno, desde o início dos seus estudos na área profissional pela qual optou, servindo de instrumento para reduzir a evasão;

- melhor condição de efetivo aprendizado para o trabalho e de qualificação para o atendimento às demandas da sociedade como um todo;

- pode ser de grande utilidade para induzir à visão crítica do profissional, com vistas às necessárias mudanças econômicas e sociais no ambiente em que esteja prestando seus serviços;

- como o processo de construção da grade curricular deve ser um exercício de grupos de trabalho, constituídos pelos docentes do curso na instituição de ensino, é de se esperar que haja maior conhecimento das características do curso como um todo, por cada docente. Isso pode promover maior interação entre docentes e entre docentes e alunos do curso, com possíveis reflexos na qualidade do ensino e no real aprendizado.

\section{Referências}

BOTOMÉ, S. P. Delimitando o que os alunos necessitam aprender no ensino superior $e$, por isso mesmo, o que os professores precisam ensinar. Curitiba: Pontifícia Universidade Católica do Paraná, 1999. (Reprografado: documento para uso interno em oficina de aprendizagem voltada ao aperfeiçoamento de professores).

BUENO, F. da S. Minidicionário da língua portuguesa. Ed. rev. e atual. São Paulo: FTD, 1996.

BRASIL. Conselho Federal de Medicina Veterinária - Diretrizes Curriculares para o Curso de Zootecnia. Brasília: In: Diretrizes Curriculares para o curso de Medicina Veterinária e Zootecnia. Brasília: Conselho Federal de Medicina Veterinária. p. 2943, 1999.
BRASIL. Ministério da Educação e do Desporto. Secretaria de Educação Média e Tecnológica. Competência do Curso Técnico Agrícola - habilitação em Zootecnia. Uberaba: Escola Agrotécnica Federal de Uberaba/MG, 1997. (Apostila reprografada).

GOLEMAN, D. Inteligência Emocional. Rio de Janeiro: Objetivo, 1995.

MARQUES, C. J. Uma concepção de currículo para modular o futuro. Educação Brasileira, Brasília, v . 20, n. 40, p.93-105, jan./jul., 1998.

MORAN, J.M. Mudar a forma de ensinar e de aprender. Transformar as aulas em pesquisa $\mathrm{e}$ comunicação presencial virtual. Disponível em http://www.eca.usp2.br/prof/moran, 1999.

PARANÁ. Secretaria de Estado da Educação. Departamento de Ensino de Segundo Grau. Programa de Expansão, Melhoria e Inovação do Ensino Médio (PROEM). Currículo: Educação Profissional. Curitiba : Governo do Estado do Paraná. Secretaria de Estado da Educação -SEED, [199?] (Apostila reprografada).

PARANÁ. Secretaria de Estado da Educação. Superintendência da Educação. Departamento de Ensino de Segundo Grau. Programa de Expansão Melhoria e Inovação do Ensino Médio (PROEM). Curso Técnico em Pecuária. Curitiba : Governo do Estado do Paraná - SEED, 1998. (Trabalho apresentado como resultado conclusivo de serviço de consultoria/Apostila).

UNESCO. Organização das Nações Unidas para Educação, Ciência e Cultura. Declaração Mundial sobre Educação Superior no Século XXI: Visão e ação. In: CONFERÊNCIA MUNDIAL SOBRE EDUCAÇÃOSUPERIOR. (1998, Paris). Marco referencial. Piracicaba : UNIMEP. p.09 - 18, 1998. 